\title{
Preparando o banquete, sonhando a festa: memória e patrimônio nas festas quilombolas (Cachoeira-Bahia)
}

\section{Francesca Bassi ${ }^{1}$ \\ Universidade Federal do Recôncavo da Bahia}

Fátima Tavares ${ }^{2}$

Universidade Federal da Bahia

Resumo: O objetivo deste artigo é compreender como dois eventos festivos de duas comunidades quilombolas da Bacia e Vale do Iguape de Cachoeira (Bahia, Brasil) articulam inovação e tradição, etnicidade e cultura de cunho popular. Os eventos mobilizam uma memória associada tanto à emergência dum campo étnico quilombola, quanto a uma reflexividade sobre as formas possíveis de patrimonialização da cultura local. As observações das duas festas serão pontuadas com comentários sobre como são performados aspectos mnemônicos, simbólicos e afetivos.

Palavras-chave: Quilombo; festa; etnicidade; memória; patrimônio imaterial.

\footnotetext{
1 Ph.D. em Antropologia pela Universidade de Montréal. Professora Adjunta do Centro de Cultura, Linguagens e Tecnologias Aplicadas da Universidade Federal do Recôncavo da Bahia, Brasil. Pesquisadora do Mesclas (UFRB) e do ObservaBaía (UFBA). E-mail: f.yansa@gmail.com

2 Doutora em Ciências Humanas (Antropologia) pela Universidade Federal do Rio de Janeiro. Professora Associada do Departamento de antropologia e da Pós-graduação em Antropologia da Universidade Federal da Bahia, Brasil. Pesquisadora do ObservaBaía (UFBA). E-mail: fattavares@ufba.br
} 


\title{
Preparing the feast, dreaming the party: memory and heritage in the quilombola festivities (Cachoeira-Bahia)
}

\begin{abstract}
The objective of this paper is to understand how two festive events of two quilombolas communities of the Basin and Valley of Iguape (Municipality of Cachoeira, Bahia, Brazil) combine innovation and tradition, ethnicity and popular culture. The two festivities enact a memory that can be associated to an ethnicity field and to a native reflexivity about the possible forms of cultural patrimonialization. The observations of the two events will be illustrated with some comments about how mnemonic, symbolic and affective aspects are performed.
\end{abstract}

Keywords: Quilombo; festivity; ethnicity; memory; intangible heritage.

\section{Preparando el banquete, soñando la fiesta: memoria y patrimonio en las fiestas quilombolas (Cachoeira-Bahía)}

Resumen: El objetivo de este artículo es comprender como dos eventos festivos de dos comunidades quilombolas de la Cuenca y Valle del Iguape de Cachoeira (Bahía, Brasil) articulan innovación y tradición, etnicidad y cultura de cuño popular. Os eventos movilizan una memoria que puede ser asociada tanto a la emergencia de un campo étnico quilombola, como a una reflexividad sobre las formas posibles de patrimonialización de la cultura local. Las observaciones de las dos fiestas serán puntuadas con comentarios sobre cómo son performados aspectos mnemónicos, simbólicos e afectivos.

Palabras clave: Quilombo; fiesta; etnicidad; memoria; patrimonio inmaterial. 


\section{Introdução}

Este artigo nasce como reflexão sobre a emergência de uma memória quilombola nas festas de duas comunidades da Bacia e Vale do Iguape de Cachoeira (Bahia). A pesquisa contemplou a participação a duas edições da Festa da Ostra na comunidade do Kaonge (outubro 2015 e setembro de 2016), festival gastronômico cunhado recentemente, e a parceria na elaboração do projeto de resgate da Festa de São Roque no Engenho da Ponte. Neste segundo caso a pesquisa acompanhou a produção do evento, cujos elementos vão constituir também matéria de reflexão sobre a recuperação de símbolos da cultura popular em chave étnica3. Apresentaremos inicialmente as comunidades da Bacia do Iguape organizadas em torno do Conselho Quilombola. Iremos depois enunciar algumas das características da Festa da Ostra (Kaonge) para, em seguida, passar a descrever a programação da Festa de São Roque (Engenho da Ponte). Buscaremos entender como os dois eventos festivos, diferentes em articular tradição e inovação, agenciam um "campo étnico-quilombola" (Marinho, 2016:156) que pode ser associado, em modos diferentes nos dois contextos, a uma emergência identitária e política (Arruti, 1997; 2008), entremeada à reflexividade nativa sobre as formas possíveis de patrimonialização (Adell, 2011) a partir de uma ressemantização de elementos da "cultura popular" em prol de uma afirmação identitária. As observações comparativas das duas festas serão pontuadas com breves comentários sobre as transformações festivas em outros quilombos da região, com a intenção de mostrar movimentos e contrastes entre as diversas formas de apresentar e transformar elementos das tradições populares locais.

Durante a pesquisa foram efetuados deslocamentos de perspectivas para desdobrar as "questões" (Perez, 2012) que emergiram nas festas, considerando tanto os momentos coletivos das festividades, como as intenções e as disposições emocionais dos interlocutores mobilizados através destas. Com efeito, considerando que a festa "faz" coisas ao invés de apenas "expressar" aspectos estruturantes do social (Tavares \& Bassi, 2015), no momento em que se fazem projetos festivos ou se vivenciam festas, também se pensam e se mobilizam processos mnemônicos, simbólicos, afetivos, sociais e políticos, segundo uma inventividade (Wagner, 2010) capaz de captar elementos populares para a encenação festiva de uma etnicidade quilombola.

\section{As comunidades quilombolas}

As comunidades quilombolas da Bacia e Vale do Iguape estão localizadas no município de Cachoeira/Bahia, no entorno da Baía de Todos os Santos e da Reserva Extrativista (RESEX) Marinha Baía do Iguape. Desde 2008, treze comunidades, localizadas no distrito de Santiago do Iguape, estão

\footnotetext{
${ }^{3}$ Um projeto de revitalização da Festa de São Roque concorreu no Edital "Itaú Cultural”, em 2016. O projeto foi fruto de uma parceria entre o Conselho Quilombola da Bacia e Vale do Iguape de Cachoeira, BA, organização civil das comunidades quilombolas dessa região e os pesquisadores do Núcleo ObservaBaía (Universidade Federal da Bahia). Desde 2013, os antropólogos desse Núcleo vêm desenvolvendo atividades de pesquisa acadêmica nas comunidades e estabelecendo parcerias para a melhoria das condições de vida e do reconhecimento dos direitos quilombolas.
} 
compreendidas no Conselho Quilombola da Bacia e Vale do Iguape4 (Kaonge, Kalembá, Kaimbongo Velho, Kalolé, Dendê, Imbiara, Engenho da Ponte, Engenho da Praia, Engenho da Vitória, Tombo, Engenho Novo, Engenho da Cruz e Brejo da Guaiba)5. As tradições culturais ancestrais (festivas, religiosas, estéticas, artesanais, culinárias, organizativas e produtivas) articulam-se com iniciativas educativas organizadas pelas próprias comunidades que valorizam o fortalecimento da cidadania na luta por políticas públicas inclusivas. Nesses territórios quilombolas observam-se iniciativas importantes em torno da economia solidária (através de vários núcleos produtivos e do Banco Solidário Quilombola, com a moeda social "sururu") e da sustentabilidade socioambiental (especialmente no contexto da RESEX)6.

O envolvimento local com a valorização de uma cultura quilombola (especialmente nas comunidades do Kaonge, Dendê, Kalembá, Engenho da Ponte e Engenho da Praia) vem propiciando ao longo dos últimos anos o fortalecimento de manifestações festivas e pedagógicas (festas, samba de roda, dança "afro", "rodas de conversa" etc.), artesanais (artigos de vestuário, comidas típicas, objetos ornamentais), terapêuticas tradicionais (plantas medicinais, xaropes de ervas, rezas etc.). Saberes, competências e habilidades são veiculados pelos mestres griôs7 que promovem a circulação de conhecimentos, contos, cantigas, e rezas pelas comunidades. Atualmente vários griôs propulsionam o turismo étnico de base comunitária designado como "Rota da Liberdade", cujo projeto é o acolhimento nas comunidades de turistas do Brasil e do exterior para convivência e participação a oficinas de artesanato e passeios temáticos de cunho cultural8. As iniciativas pioneiras do Centro de Educação e Cultura Vale do Iguape (CECVI) 9 e do Conselho Quilombola vem fortalecendo as expressões culturais dessas comunidades, resgatando tradições populares, memórias ancestrais e incrementando novas edições de eventos e atividades (festivos, religiosos, políticos, educativos, artísticos etc.). Nesse contexto de resgate da cultura popular, destacam-se a importância da transmissão oral da memória e a participação comunitária no ritualismo católico e afro-brasileiro, que articulamse com o conjunto das manifestações festivas lúdicas e artísticas. Como veremos, uma certa relação entre patrimônio imaterial e identidade quilombola se faz pelo viés de vivencias comunitárias e religiosas performadas no contexto dos eventos festivos.

\footnotetext{
${ }^{4}$ Organização civil sem fins lucrativos que tem como principais finalidades a defesa dos direitos comunitários, a garantia do acesso à terra, a preservação dos bens materiais, imateriais e dos ecossistemas de que dependem essas comunidades para seu desenvolvimento com sustentabilidade. Para maiores detalhes sobre o Conselho Quilombola, ver: <http://www.rotadaliberdade.net/conselho-quilombola-da-bacia-e-vale-do-iguape/>. Acesso em: 01 nov. 2015.

${ }^{5}$ As comunidades ocupam a região desde os tempos do Brasil Colônia, tendo sido formadas por negros escravizados dos engenhos e fazendas de cana de açúcar da região, constituindo atualmente territórios quilombolas certificados pela Fundação Cultural Palmares Para uma análise das transformações da condição social dos negros escravizados na região, entre o final do século XIX e primeiras décadas do século XX, ver Fraga Filho (2006).

6 A produção agrícola e extrativista se realiza sem uso de agrotóxicos e de forma artesanal e solidária (mel, ostras, pescados e mariscos, farinha de mandioca, quiabo, azeite de dendê). A economia das comunidades conta também como a criação de gado e de pequenos animais.

${ }^{7}$ Como pode-se ler no site http://www.leigrionacional.org.br/o-que-e-grio/ (Acesso em: 10 fev. 2017): “O termo Griô é (...) uma corruptela da palavra "Creole", ou seja, Crioulo, a língua geral dos negros na diáspora africana (...) O termo griô tem origem nos músicos, genealogistas, poetas e comunicadores sociais, mediadores da transmissão oral”. No Brasil os griôs conseguiram um novo estatuto e uma nova dignidade com a proposta, e aprovação em 2014 da "Lei Griô".

${ }^{8}$ Sobre o núcleo de produção de turismo étnico de base comunitária "Rota da Liberdade", ver sítio na internet: <http://www.rotadaliberdade.net/>. Acesso em: 01 nov. 2015.

${ }^{9}$ A fundação do CECVI foi promovida pela Companhia de Dança Quilombola do Vale do Iguape, no intuito de ter uma organização registrada juridicamente para promoção de suas atividades. Ver atividades do CECVI em sítio da internet: <http://www.cecvi.org.br/>. Acesso em: 31 out. 2015.
} 


\section{A Festa da Ostra}

A Festa da Ostra é um evento de expressiva visibilidade (para além do contexto local) e faz parte do calendário de eventos do "turismo étnico" divulgados na região. A festa, que mobiliza tanto as comunidades quilombolas quanto as redes mais amplas de parentela e amizade que se estendem até Salvador, ocorre na comunidade do Kaonge. No espaço físico deste quilombo encontra-se uma escola e um terreiro de umbanda, o que comporta uma permanente afluência no local de pessoas de outros quilombos. De fato, trata-se de uma comunidade bem organizada em torno da promoção da cultura quilombola através de projetos de turismo étnico e expressões de engajamento político, tornando-se assim ponto de referência para muitas pessoas das comunidades do entorno. A festa é organizada pelos cultivadores de ostras, pelo núcleo de Turismo Étnico Rota da Liberdade e pelos demais núcleos produtivos existentes nas comunidades quilombolas, mobilizando vários quilombos que aderem ao Conselho. Em 2015 e 2016, na sua VII e VIII edições, pudemos assistir a importantes experimentos associativos $\left(1^{\circ} \mathrm{e} \quad 2^{\circ}\right.$ Encontros de Lideranças das Comunidades Quilombolas do Território de Identidade do Recôncavo e agenda de reivindicação junto a políticos locais e funcionários estaduais); de economia solidária (venda de produtos das comunidades); culinários (oficinas de comidas típicas, degustação de ostras), artísticos e performáticos (rodas de capoeira, grupos de samba de roda, dança afro, apresentação da performance do "Nego Fugido"10, da comunidade quilombola do Acupe, apresentação das "Caretas do Paraguaçu", shows de reggae); estéticos (decoração do evento, desfile com indumentária afro); lúdicos ( brincadeiras infantis, leilões).

A Festa da Ostra pode ser compreendida tanto a partir do conceito de "invenção da tradição" (Hobsbawm \& Ranger, 1982), quanto a partir das contribuições de Wagner (2010) sobre inventividade inerente aos processos de simbolização da cultura. A festa em questão remete a diferentes modos de atuação dos símbolos extraídos da cultura popular, reinterpretados como parte do patrimônio quilombola. Condensa-se modalidades comunicacionais tradicionais e modernas, que se distribuem no contexto espaço temporal do evento. Assim, para a divulgação da festa, se faz uso de meios de comunicação contemporâneos (com transmissão on line, na festa de 2016), buscando-se, eventualmente com a colaboração de guias turísticos, receber turistas nacionais e estrangeiros11. Durante seu andamento, a própria festa é "curtida" nas redes sociais, os jovens das comunidades sendo prepostos a monitorar o impacto das festas no ambiente virtual. Todavia, este uso da mídia não desmente o apego às expressões da cultura oral tradicional pelos mais velhos das comunidades que promovem, durante a festa, "rodas de conversa". As "rodas", lideradas pelos mestres griôs reconduzem, como uma força centrípeta, a festa no interior da comunidade, pois reforçam uma sociabilidade comunitária e o sentimento de pertencimento à um território ancestral.

Enquanto celebração das atividades tradicionais da economia quilombola (o cultivo e a pesca da ostra, mas também a produção da farinha de mandioca, do dendê, do cultivo do quiabo, etc.), a festa evoca tanto uma tentativa de dar

\footnotetext{
${ }^{10}$ Espetáculo da cultura popular de Acupe (Santo Amaro, Bahia) que funde elementos da dança, da música, símbolos do candomblé, pinturas corporais, etc. Durante a performance é encenada a luta dos escravos pela libertação.

${ }^{11}$ Ver, por ex., <http://ecoviagem.uol.com.br/noticias/turismo/gastronomia/reconcavo-baiano-tradicao-ostras-equilombo-13695.asp >. Acesso em: 03 fev. 2017.
} 
visibilidade às formas de produtividade artesanal (o cultivo da ostra continua sendo praticado segundo as técnicas de pesca artesanal como a "camboa de pau”), quanto um modelo moderno de festival eco gastronômico. Vale lembrar, sobre este último ponto, o interesse pela culinária quilombola do fundador do movimento internacional Slow Food International, o italiano Carlo Petrini, e a certificação de qualidade superior do azeite de dendê obtida pelas comunidades junto a essa organização12. Deste modo, os saberes e fazeres comunitários, associados à produção artesanal e à culinária afro-brasileira, agenciam a emergência de uma identidade quilombola, valorizando maneiras ancestrais de subsistência. Ao mesmo tempo, com a adesão aos critérios e certificações internacionais de sua autenticidade, estes saberes e fazeres se redefinem na esfera da patrimonialização imaterial13.

Os marcos da produção e da gastronomia local adquirem uma dimensão festiva através dos aspectos lúdicos, artísticos e performáticos citados, que marcam o espaço e o tempo da festa e dão contorno ao tema gastronômico central do evento: o consumo de ostras cruas ou assadas na brasa e o almoço baseado nas iguarias afro-brasileiras (moqueca de ostra e de sururu, caruru, vatapá, arroz e feijão). A festa também prevê celebrações de cunho religioso e ritualístico: há celebração da missa católica no primeiro dia; são homenageados os Orixás com cantigas; há uma forte implicação emocional na preparação do tradicional caruru. O caruru, iguaria preparada com quiabos, é ofertado aos santos Cosme de Damião, sincretizados com os Ibejis, entidades gêmeas, cultuadas nas religiões afro-brasileiras e presentes na religiosidade se cunho popular da região14. A feição eco gastronômica, artística e lúdica da festa tem, sem dúvida, uma dimensão turisticamente accessível e suscita impacto no visitante. Todavia, o citado ritualismo votivo da religiosidade afro-brasileira fundamenta, para os próprios quilombolas, o evento festivo, pois define a festa como pagamento de uma promessa, associando o evento às aspirações comunitárias. A festa é assim reconduzida à tradição dos carurus que, como veremos, mobilizam uma importante dinâmica de reciprocidade ligada às ações devocionais e religiosas de cunho popular.

Os diversos vultos da Festa da Ostra podem, de uma forma ou de outra, ser avaliados como expressões de uma identidade quilombola, pois tanto a culinária como o artesanato, e as várias performances são trazidas no "palco" da festa como expressões de uma cultura negra local. Conforme Boissevain (1992, 2014) aponta, os fenômenos modernos de revitalização das tradições festivas e ritualísticas apresentam um incremento eventual dos aspectos lúdicos e diminuição do formalismo religioso. Analisada sob este aspecto, a Festa da Ostra apresenta uma dinâmica "moderna" enquanto festival gastronômico, comercial e artístico, todavia, como veremos melhor adiante, atrás dos bastidores, o evento é propulsionado pela mencionada tradição ritualística de banquetes votivos (os carurus) da tradição afro-brasileira presente na região, segundo uma dinâmica de continuidade cultural. Outros contrastes conceituais

\footnotetext{
${ }^{12}$ Ver <http://www.slowfoodbrasil.com/textos/slow-food-na-midia/796-a-politica-mais-importante-passa-pelacomida-carlo-petrini>. Acesso em: 26 nov. 2016.

${ }^{13} \mathrm{O}$ italiano Carlo Petrini, fundador da Slow Food, sobre as ostras saboreadas durante uma edição da festa, declara: "Penso que merecem uma denominação de origem [Denominação der Origem Controlada, designação atribuída a produtos de determinadas regiões, que cumprem uma legislação própria]. Este produto é a expressão de um território. Uma ostra assim só pode nascer ali, não em outra parte”. Disponível em:< (http://www.slowfoodbrasil.com/textos/slow-food-na-midia/796-a-politica-mais-importante-passa-pela-comida-carlopetrini>. Acesso em: 03 fev. 2017.

${ }^{14}$ A celebração do caruru prevê uma grande quantidade de quiabos cozidos, condimentados com azeite de dendê, cebola, alho, amendoins e castanhas de caju moídas, gengibre, camarões secos, coentro e pimenta; o caruru é geralmente acompanhado por acarajé, abará, carne, frango ou peixe.
} 
da festa poderiam ser evocados, todavia este artigo não pretende ser exaustivo neste sentido. Mais especificamente, nosso objetivo é apresentar uma etnografia de duas festas (da Ostra e de São Roque) para tracejar como, junto ao valor afetivo das interações, ao valor persuasivo das falas, ao valor estético das performances, se faz a memória de uma identidade quilombola segundo uma especifica mobilização de elementos cuja encenação festiva remete tanto à construção de um campo étnico como a uma reflexividade sobre o patrimônio e a uma renovada valorização dos saberes e fazeres locais.

\section{A estrutura da Festa da Ostra, os organizadores e os participantes}

A estrutura da Festa da Ostra pode ser pensada segundo um desdobramento entre atividades contínuas e pontuais. Na primeira categoria temos, além da citada venda de objetos de artesanato e produtos alimentares, a consumição gratuita de ostras cruas e assadas (em 2015 foi realizada numa clareira próxima às casas e em 2016, ficou restrita à oficina culinária). Como atividades pontuais, destacam-se as oficinas (feitura de dendê, formação de mestres griôs, ervas medicinais, formação em turismo étnico e cultivo de ostras), as citadas performances musicais e teatrais de cunho popular e os debates políticos. A participação de representantes institucionais (políticos locais e funcionários estaduais) durante $0 \quad 1^{\circ}$ Encontro de Lideranças das Comunidades Quilombolas no sábado de manhã (3 de outubro 2015) caracterizou a parte mais solene do evento; os sambas e shows musicais durante a tarde e à noite (e também no dia seguinte) foram expressando os aspectos mais lúdicos e recreativos da festa que abrangeu, nesses momentos, uma participação ampla.

Reconhecíveis pelo uso de vestimentas com padrões estéticos africanos (em 2015 teve também desfile de moda quilombola), os anfitriões da festa (jovens e mais velhos) são, na maioria, parentes ou pessoas muito próximas de dona Juvani, a mãe-de-santo do terreiro Umbanda do Kaonge, também Mestra Griô, ex-professora e líder comunitária muito respeitada (entre os organizadores, além de irmãos, filhos e sobrinhos de Juvani, contam-se afilhados e filhos "espirituais", isto é, iniciados na umbanda)15. Os participantes mais assíduos (os que voltam a cada ano e são hospedados no próprio quilombo) pertencem ao círculo de parentes e amigos dos moradores. Muitos deles vêm de Salvador e aproveitam da Festa da Ostra para passar um fim de semana entre amigos e parentes, longe da cidade - às vezes qualificando a própria participação à festa com um certo saudosismo da vida rural e familiar. Em algumas entrevistas que realizamos durante as festas, as falas destes participantes assíduos foram ricas de elogios relativos ao ambiente festivo; foi também notada a satisfação que acompanhava os momentos descontraídos das "festinhas" dentro da festa: os churrascos e as conversas entre pequenos grupos de parentes e amigos próximos reunidos ora numa casa, ora em outra (como foi observado no domingo, segundo dia da festa de 2015). A festa tendeu, assim, a confluir em mais uma "questão" (Perez, 2010): aquela da afecção pelo local dos

15 Todos os interlocutores da pesquisa mencionados neste trabalho são apresentados por seus nomes ou apelidos verdadeiros, conforme desejo manifestado pelos quilombolas, configurando uma das cláusulas do "contrato de pesquisa” (e parceria) firmado entre o Conselho Quilombola e o Núcleo ObservaBaía em janeiro de 2014. 
quilombolas "expatriados" que voltam ao quilombo compartilhando horizontes identitários num tempo forte, quando a sociabilidade se faz intensa e os vínculos de parentesco ou de amizade são reforçados. Em vários depoimentos, os participantes, notadamente aqueles que diziam ter laços de parentesco com os moradores do Kaonge, sentiram também a necessidade de enfatizar, além do alto valor artístico e lúdico do evento, o lado espiritual e religioso dos momentos vivenciados, especialmente durante a preparação do caruru na véspera do primeiro dia da festa (sexta-feira). Em diversas conversas, a liderança da Mãe de Santo, mulher carismática, foi elogiada. De fato, para os visitantes próximos à Juvani (por parentesco ou por laços antigos de vizinhança), a própria festa é uma celebração de uma tradição religiosa local encarnada em sua própria liderança, comunitária e religiosa.

Uma árvore sagrada enfeitada com panos rituais em frente à casa que abriga o barracão do terreiro de umbanda evoca o "habitar" desse quilombo, emaranhando o ambiente à ancestralidade e à sua abertura para o presente e o futuro (Ingold, 2015), pois Juvani gosta de sublinhar como sua luta pelos direitos quilombolas extrai sua força do reconhecimento das raízes africanas de sua religiosidade. $\mathrm{O}$ culto dos orixás promovido por Juvani, ao mesmo tempo que dá visibilidade à identidade negra, aglutina, como veremos logo a seguir, as devoções populares presentes nas comunidades na construção duma religiosidade de matriz africana capaz de delimitar um campo étnicoquilombola.

\title{
Preparando o banquete: a emergência da festa
}

Na véspera da festa em 2015, quando Juvani abriu a "roda de conversa" (discussões sobre questões sócio-políticas e sobre a realidade quilombola), as mulheres das comunidades já estão ocupadas a cortar o quiabo para o preparo o caruru, iguaria que compõe o cardápio do almoço da festa. É um momento de sociabilidade comunitária intensa, pois elas vão virar a noite no preparo do "Caruru de Vungi"16. O caruru e, em geral, os pratos da tradição africana são preparados com uma devoção apta a respaldar, com uma dimensão altamente comemorativa, a "invenção" da festa da Ostras. Como se depreende nas palavras de Juvani17:

\begin{abstract}
Ajeum é o termo iorubá destinado às refeições. Sua tradução mais literal é "banquete" e constitui o ato de comer e dar de comer às entidades pelo seguidores dos cultos afro-brasileiros. (...) Na Festa da Ostra, comemorou-se os 8 anos de conquistas após a primeiro caruru de Vungi, realizado em 2005. Após esta data, as comunidades do Vale do Iguape, conquistaram a luz elétrica, a água potável encanada e agora mais uma conquista, a construção de 49 casa através do programa Minha Casa Minha Vida Rural, além de vários projetos de sustentabilidade, e ações sociais como o Ponto de Cultura e os núcleos de produção do Azeite de Dendê, Turismo Étnico, Apicultura, Artesanato, Agricultura, Cultivo de ostra, pesca e outras conquistas para a sustentabilidade com base comunitária. Assim, na $V$ Festa da Ostra, foi mais uma vez servido para os convidados $e$ prestigiadores, o ajeum, saboreando também as moquecas da culinária quilombola.
\end{abstract}

A festa da Ostra, celebrando a produtividade local, devolve ao mesmo tempo, uma imagem da luta quilombola. Os efeitos propagam-se pelo cotidiano

\footnotetext{
${ }^{16}$ Vungi, na nação Angola, ou Ibeji na nação Keto, são divindades infantis: regem alegrias, mas também provocam empecilhos quando descuidadas.

${ }^{17}$ Depoimento disponível no site do CECVI.
} 
dos agentes envolvidos, pois, para além da festa, o que está em jogo são os direitos conquistados, as metas econômicas alcançadas, o fortalecimento da organização sociopolítica dos quilombolas, o reconhecimento de um patrimônio imaterial capaz de afirmar uma identidade étnica. Todavia, todas essas diversas 'questões da festa' (Perez 2012) se respaldam numa performance local de cunho devocional e ritualístico, que favorece a emergência de uma realidade comunitária que deseja expressar sua especificidade: o ajeum, isto é, o banquete devocional de origem africana. O caruru parece assim reconduzir a Festa da Ostra para dentro da comunidade numa dimensão evocativa de uma "essência" identitária. Ritual interno à festa, a oferenda remete a um comportamento performativo que, além de ser simbólico e reflexivo (Schechner, 2013), catalisa uma presença comunitária intensa e íntima, pois trata-se de um momento interno à comunidade e preparativo do evento, indispensável para a fundação da festa no seu conjunto18. É licito, portanto, recuperar esta dimensão comunitária da oferenda reconsiderando o valor transformativo (e não unicamente representativo) de símbolos e de atos de cunho ritualístico (Tavares \& Bassi, 2013). Antes que tudo, vale pensar ao ritual como ação transformativa (Peirano, 2006) sem, evidentemente, reduzir a festa a um âmbito religioso ou ritualístico, sabendo que "há rituais nas festas e há festas nos rituais" (Severi, 2005) 19. Como enfatiza ainda Severi:

\begin{abstract}
A festa contém certos aspectos interessantes de um fenômeno central da antropologia: o rito. O rito suscita a presença de algo de invisível, a festa parece mais que uma interação coletiva. Mas [...] muitas festas não são simplesmente um conjunto interações, elas carregam uma definição coletiva de uma presença à qual, talvez de forma cientemente, talvez de forma mais inconsciente, os participantes se refere" (2005:1).
\end{abstract}

O ato originário de cunho ritualístico, isto é, a preparação do Caruru de Vungi é, para seus organizadores, a maneira de impregnar a fundação da Festa da Ostra com a definição coletiva de uma presença: a comunidade quilombola na sua plenitude (nas suas metas alcançadas, como a Juvani expressa na sua fala). Uma certa verdade está sendo assim reiterada num registro performativo e ritualístico que condensa várias instâncias: convocando entre os humanos a ação protetora de Vungi, a oferenda indica entre os devotos a presença de uma identidade comunitária que se espelha tanto na proteção das entidades como no alcance dos seus objetivos. Uma presença quilombola plena se faz concreta nesse momento (em caso contrário ficaria mais indefinível e impalpável) e vai se articular com as outras instâncias da festa (suas políticas, sua economia, sua estética, etc.). De fato, a inovadora festa gastronômica da Ostra atua igualmente na emergência de uma identidade social, isto é, no processo e na construção de uma memória coletiva. $\mathrm{O}$ ato fundador - o banquete- permitiu, de fato, articular a festa com o memorável e o comemorável, como enfatizam as palavras já citadas de Juvani: "Na Festa da Ostra, comemorou-se os oito anos de conquistas após ao primeiro Caruru de Vungi” (ibidem).

\footnotetext{
${ }^{18} \mathrm{O}$ valor tradicional do trabalho comunitário inerente à festa é enfatizado pela própria Juvani: "A festa da ostra se tornou um evento eco gastronômico, graça a uma grande tradição que adotamos, a do trabalho coletivo", ela afirma, considerando o envolvimento no preparo da festa, das comunidades. Juvani também valoriza outros momentos de intro-flexão comunitária, notadamente, durante o preparo do citado caruru devocional. Disponível em: http://www.slowfoodbrasil.com/textos/noticias-slow-food/803-festa-da-ostra-na-comunidade-quilombola-do-kaonge. Acesso: 15 de fev. 2017. Sobre a diferença, e eventual alternância, entre o festival gastronômico de cunho moderno e laico e consomo ritual de um banquete devocional, ver Di Renzo (2006).

${ }^{19}$ Ver entrevista de Martino Doni a Severi (2005). Como indica Severi, há distinções entre uma série de fenômenos heterogêneos que chamamos "festas": os que se organizam através do conceito de eficácia ritual e os que enfatizam o aspecto dos afetos e do vínculo.
} 


\section{A Festa de São Roque: a transmissão oral e a competência Griô}

Para os quilombolas fazer a festa sempre foi uma maneira fundamental de vivenciar a comunidade; hoje em dia a festa também "faz" o campo étnicoquilombola segundo maneiras de acionar um repertório de referência e estimular um saber performático. A festa de São Roque já mobilizou vivências comunitárias enraizadas em modos específicos de transmissão oral de saberes artísticos e religiosos (cantigas, toques musicais, danças, rezas). Considerando que é por meio da valorização e desenvolvimento dessas habilidades que a festa acontece em sua plenitude, deve-se enfatizar a confluência entre o resgate dessas competências e a produção da festa20. Na descrição da festa de São Roque, que se estrutura em diferentes momentos ("esmola cantada", nos finais de semana anteriores à festa, além das atividades dos dois dias da festa: baile, missa e procissão), deve ser, ainda, especialmente destacada a importância da atuação dos mestres griôs para a transmissão das memórias comunitárias sobre a origem da festa e na "feitura" do próprio evento festivo (Moura, 2012). Os mestres das comunidades ressaltam que a festa de São Roque não pode ser dissociada da tradição da história contada, isto é, do costume dos mais velhos de narrar as histórias sobre os acontecimentos milagrosos associados aos atos de devoção dirigidos ao Santo. Seu resgate atual remete à reflexividade desses mestres em relação ao patrimônio imaterial quilombola e às particularidades pedagógicas da transmissão oral, cujo desaparecimento está comprometendo, segundo eles, os momentos festivos comunitários.

Evidentemente, na transmissão oral elementos linguísticos e extralinguísticos -a prosódia das palavras, os sons presentes nos lugares- afetam os corpos e o sensibilizam para novos conhecimentos e habilidades, fluindo numa pedagogia nativa centrada na performatividade da transmissão oral e na educação à atenção (Ingold 2010)21. A transmissão oral favorece o compartilhamento da experiência vivida, promovendo momentos de intersubjetividade, fundamentais para a comunicação dessas "epistemologias e práticas nativas que realizam (enact) a unidade de sentir, pensar e fazer" (Schechner, 2013:39). A performatividade inerente ao contar histórias, portanto, investe a devoção de São Roque de uma experiência incorporada e comunitária, que aponta para o conto como atividade lúdica e pedagógica, conectando este tipo comunicação à uma identidade local (geralmente rotulada como "popular" mas, neste contexto, vivenciada como quilombola), em contraste com modos de transmissão dominantes.

\footnotetext{
20 Sobre o tema da festa, ver Amaral (1988), Duvignaud (1983), Perez (2012), Tavares (2012), Tavares \& Bassi (2015).

${ }^{21}$ A antiga maneira quilombola de transmitir saberes locais pode ser comparável aos relatos de Pouget \& Ramos quando descrevem os anciões indígenas Hupd'äh (Rio Negro): “Durante as caminhadas, as interações com animais através da caça e da pesca, com os diversos seres míticos e paisagens demonstraram a necessidade de uma reflexão sobre os modos de percepção do ambiente vinculados a uma noção abrangente de ancestralidade" (2014:7).
} 


\section{O conto: a origem da festa na devoção ao "Pé do Velho"}

A própria origem da festa de São Roque evoca os acontecimentos que marcaram profundamente a comunidade quilombola do Engenho da Ponte, decorrente de atos de devoção relacionados a surtos de varíola, sarampo e catapora ainda no início do século XX. Nessa comunidade existe um pé de gameleira e um poço de água curativa, local conhecido pelo nome de "Pé do Velho", onde os negros escravizados se reuniam para fazer suas rezas, oferendas e outras obrigações rituais. De fato, na estrutura oral da história contada é possível enxergar a possibilidade de produzir e reproduzir uma "arte da memória" (Severi,1985:183), isto é, um itinerário mental que desfruta de técnicas de memorização, isto é, de associações de certos símbolos e imagens (a figura mítica de Omolu, notadamente) a lugares específicos (o "Pé do Velho”)22.

Segundo nossos interlocutores23, os "antigos" do Engenho da Ponte, todo mês de agosto (mês dedicado ao Omolu, orixá "velho" associado aos surtos da varíola e às epidemias) aparecia um homem idoso descalço andando lentamente pela comunidade com um saco de linhagem, uma cabaça na costa e uma cuia na mão pedindo esmola nas casas. A grande mortandade de crianças e adultos provocada pelas epidemias fizeram com que as pessoas desse lugar reconhecessem naquele velho um sinal da devoção ao Omolu, sincretizado com São Roque. Os moradores se reuniram, então, ao "Pé do Velho" e fizeram uma promessa a São Roque, pedindo para pôr fim à mortandade e prometendo a realização da festa em seu louvor.

Voltando a própria festa de São Roque, vale lembrar que, embora seja a festa mais antiga das comunidades quilombolas dessa região, durante os anos de 1990 e 2000 ela não aconteceu, vindo a ser resgatada em 2009 por iniciativa dos moradores do Engenho da Ponte, estimulados pela então nascente organização do Conselho Quilombola. Foi durante um encontro de mestres e aprendizes griôs do "Projeto Bagagem", realizado em Lençóis (BA), em 2008, que a própria mãe de santo Juvani (que também possui título de mestra griô) sentiu-se inspirada para determinar a revitalização da Festa de São Roque por meio da "Esmola Cantada". Como ela nos relatou, a inspiração procedeu de um sonho no qual se fez clara a importância de não deixar a festa extinguir-se. A retomada da devoção a São Roque se apresenta, assim, no âmago das religiões afro-brasileiras que se apoiam tradicionalmente nas visões dos adeptos e nas revelações oníricas para estabelecer suas injunções. Elementos diversos da cultura devocional católica e sincrética fazem agora parte de um "drama espiritual" onde os orixás dominam a cena. A dona Juvani, no mesmo momento que se declara intermediaria de uma ordem superior, expõe a comunidade a uma reflexão sobre a festa de São Roque como patrimônio quilombola a ser resgatado.

\footnotetext{
22 Os interlocutores relatam também que nessa época a dona da fazenda era Elvira Novis, católica muito devota de Nossa Senhora da Conceição, promotora dos festejos à santa no dia oito de dezembro, na capela da localidade. Foi ela quem adquiriu, em Salvador, a imagem de São Roque e entregando-a para a comunidade, ajudando, assim, a promover a devoção comunitária ao santo. Anos depois, em decorrência das dificuldades de realização da festa no mês de agosto (a época chuvosa e o solo de massapê dificultavam a locomoção), a festa passou a ser realizada no mês de fevereiro, com a "anuência" de São Roque.

23 Relatos de Ananias, liderança quilombola, e de Selma, moradora do Engenho da Ponte. Nas narrativas o santo católico São Roque é sincretizado com os orixás Omolu, orixá da doença. Também é citada Nanã, os dois orixás sendo conhecidos como "os velhos".
} 


\section{A "esmola cantada" e a performance festiva}

A Festa de São Roque se inicia bem antes da sua celebração principal, comportando os eventos preparatórios da "esmola cantada", que se sucedem por quatro domingos do mês de janeiro. Para a arrecadação dos fundos que viabiliza a realização da festa principal, em cada domingo a comunidade do Engenho da Ponte percorre um trajeto específico louvando e "encantando" São Roque com contos cantados e rezas. Uma grande comitiva se organiza com tocadores de cavaquinho, pandeiro e tambor (rebolo), além dos rezadores e cantadores. Crianças, jovens, adultos e idosos saem da casa do tesoureiro (o dono da "bandeira" de São Roque, organizador da festa) e percorrem a pé longas distâncias entre as comunidades, sendo recebidos de porta em porta nas casas da comunidade visitada, onde é feito o peditório. Ao final de cada domingo, a comitiva volta a se reunir na casa do tesoureiro da comunidade do Engenho da Ponte para encerrar as atividades do dia24.

Depois dos vários domingos de "esmola cantada", a festa acontece num final de semana do mês de fevereiro. No sábado à noite dá-se início aos festejos com a apresentação de vários grupos musicais (de samba de roda, dentre outros estilos), danças, venda de comidas típicas. No intervalo do baile pode-se também participar do leilão que é realizado para arrecadação de fundos. No domingo pela manhã tem lugar a missa solene, com o padre especialmente convidado para a ocasião. Após a missa segue o grande almoço oferecido a todos os participantes, que contou com cerca de trezentos participantes de várias comunidades em 2015. Ressaltamos aqui a importância da rede de solidariedade que possibilita a arrumação e decoração da igreja, o receptivo para a refeição e a organização da procissão em seguida ao almoço.

À tarde, é a vez da procissão sair, quando as imagens de Nossa Senhora da Conceição e de São Roque são levadas em seus andores pelo percurso tradicional que atravessa toda a comunidade. As rezadeiras da procissão vão à frente do cortejo puxando as rezas próprias desta celebração. É importante enfatizar que o patrimônio imaterial constituído pelos cantos, sonoridades, ritmos e orações constitui parte fundamental desses momentos solenes.

\section{O futuro da festa: avaliando as tradições orais}

Apesar de constituir um evento altamente significativo para as comunidades quilombolas dessa região, atualmente a festa de São Roque passa por sérias dificuldades. Os recursos arrecadados na realização das "Esmolas Cantadas" só conseguem cobrir os custos de ornamentação da igreja e da procissão, além do transporte do padre. Essas dificuldades sobrecarregam os organizadores, que acabam por custear algumas dessas despesas (alimentação oferecida durante a "Esmola Cantada" e na festa propriamente dita). O patrocínio da prefeitura, por sua vez, pelo menos em 2016, se restringiu à

\footnotetext{
${ }^{24}$ Os trajetos percorridos pela comitiva variam nas distâncias. Em 2016, a programação foi a seguinte: no primeiro domingo, a comitiva vai do Engenho da Ponte até o próximo Engenho da Praia. No segundo domingo, o trajeto é bem maior, compreendendo o Engenho da Ponte, Kalembá, Kaonge, Dendê e a Capela da localidade de Campina. No terceiro domingo, uma parte do percurso deve ser feito de ônibus, pois as comunidades visitadas são distantes: Engenho da Ponte, Engenho Novo e Opalma. No último domingo, o trajeto compreende o Engenho da Ponte e Santiago do Iguape.
} 
infraestrutura de palco e de bandas musicais que nem sempre são do agrado das comunidades.

Do ponto de vista da transmissão das habilidades festivas, os moradores enfatizam as dificuldades atuais de manutenção desse patrimônio oral e consideram os cantos e rezas como verdadeiros acervos da tradição religiosa do lugar. Sem reza não pode haver procissão e a procura por rezadeiras capacitadas vem se tornando uma tarefa árdua, pois as pessoas idosas estão desaparecendo e poucos são os adultos que detém atualmente essas competências. A viabilização de certas condições materiais para a realização das atividades da "esmola cantada" e da festa propriamente dita é imprescindível para a sua continuidade e fortalecimento. Igualmente importante é a valorização da transmissão oral do conhecimento para as gerações futuras; conhecimento, este, atualmente investido na vivência de algumas pessoas já idosas das comunidades do Kaonge, Engenho da Ponte, Santiago do Iguape, dentre outras.

As dificuldades de realização da festa da Festa de São Roque e a ênfase no valor da transmissão oral se desdobra, nas falas dos interlocutores, em duas avaliações distintas, mas relacionadas. A primeira é ligada à questão da transmissão dos elementos de cultura popular presentes nos momentos da festa (cantigas e rezas, notadamente)25, pois é com angústia que os interlocutores sugerem como o desempenho de certas habilidades festivo-religiosas podem estar comprometidas com o desaparecimento dos moradores mais idosos. A segunda diz a respeito ao resgate do valor da ancestralidade e da oralidade, segundo um modelo especifico da "cultura griô". Com o citado projeto (apresentado no início deste trabalho), com nossa colaboração a um edital cultural para a revitalização da Festa de São Roque, os interlocutores enfatizaram a importância de haver "bolsas" para implementar uma pedagogia griô nos quilombos, no intuito de sensibilizar os jovens a valorizar o conceito de ancestralidade -implicado na transmissão geracional dos saberes e fazeres-, além de modos de sociabilidade e aprendizagem ligados à oralidade. $\mathrm{O}$ projeto de revitalização da Festa de São Roque gera, assim, importantes reflexões sobre a dificuldades da pedagogia tradicional e considera a tradição dos griôs uma importante alavanca para uma instauração mais formalizada de uma pedagogia oral, segundo novas maneiras de preservação da tradição oral e sua patrimonialização.

\section{Interlúdio: breve etnografia das festividades populares nos quilombos}

Nas comunidades quilombolas dessa região muitos relatos sobre festas populares costumam relacioná-las às religiosidades de matriz africana e à preparação da iguaria baiana: o caruru. Como já vimos, trata-se da comida ritual dos Ibejis (ou, alternativamente, Vunji), divindades infantis cultuadas no candomblé e na umbanda e sincretizadas com os santos Cosme e Damião. Os festejos, que além da preparação da comida ritual, incluem música e dança (samba de roda), favorecem, assim, a transmissão de habilidades culinárias e artísticas. Os carurus acontecem geralmente no mês de setembro, todavia, a data pode variar, dependendo dos acordos entre os vários participantes. As

\footnotetext{
${ }^{25}$ Sobre este tema, ver Nascimento e Ayala que sublinham, a relação entre preservação do patrimônio imaterial e a transmissão de geração em geração das práticas tradicionais (notadamente, rezas) (2013:3).
} 
festas podem às vezes incluir, além dos Ibejis, outros orixás, rendendo a preparação da comida ritual ainda mais complexa e dispendiosa. Os devotos devem combinar para não sobrepor as datas das festas, inclusive porque o trabalho na preparação das iguarias precisa de uma troca de serviços e disponibilidade do tempo alheio. De fato, a organização dos carurus depende das redes de solidariedade existentes entre vizinhos, já que a cada festa várias pessoas são chamadas a ofertar quiabos e a colaborar na preparação.

Sobre a relevância do caruru no sistema local de reciprocidade, durante entrevista, Neide, moradora do Tombo, explica que, no ano 2014, para oferecer o seu caruru, teve que mudar a data:"Eu fiz em dezembro e aí tinha muitas colegas que marcou : 'Neide, vá lá em casa que tem um caruru tal dia'. Aí eu não achei sábado, assim, sobrando pra marcar o meu. Aí eu peguei e marquei pra o vinte e sete de dezembro". Na entrevista, ela esclarece que já foi chamada para várias festas pois, além de vários carurus, podem haver, no período citado, outras oferendas, como as chamadas "farofas de Yansã", isto é, a preparação de um frango a ofertar a este orixá feminino, cuja celebração acontece no dia quatro de dezembro. Finalmente, Neide decidiu "empurrar" seu caruru, de dezembro 2015 para janeiro 2016, porque todos os sábados de dezembro já estavam ocupados pelas festas de outros conhecidos onde ela era chamada a participar, o que indica um forte comprometimento comunitário para com estas manifestações devocionais.

Segundo Neide, não haveria uma nítida identificação entre a devoção aos Ibejis e uma iniciação formalizada em terreiros de candomblé ou umbanda específicos, as oferendas para os orixás aparecendo em muitos casos ligados a um culto doméstico, marcado pela solidariedade entre devotos e por uma difusa religiosidade de cunho sincrético. Todavia, as festas apresentam também momentos típicos das sessões de candomblé, com manifestações dos orixás nas pessoas presentes. Embora Neide declare não receber entidades, aparece na sua fala um sentimento de pertencimento religioso marcado pelo ser de "dentro", isto é, "cuidar dos orixás", que é reforçado pelos convites aos carurus, quando somente quem pratica este tipo de devoção é chamado a participar, como ela esclarece: "Se todo mundo é do dentro, chama mesmo. Do dentro é assim, quer dizer, eu dou o caruru, se for a mesma coisa dela... assim... a gente cuida dos orixás, aí ela [a pessoa que convida] pega e chama”. Conforme a narrativa da interlocutora, as festas de carurus foram ainda mais numerosas no passado; ela afirma também que não conhece pessoas que fazem caruru nos quilombos Kalembá e Imbiara onde o número de "crentes" é notável. As quantidades de festas dos Ibejis marcam, de fato, um tecido social ligado a prestações de serviços e contraprestações definidas por um tipo de festividade cujas expressões artísticas e lúdicas (notadamente o samba de roda) contrastam, no contexto local atual, com os costumes austeros dos evangélicos.

Além do caruru, outros interlocutores falam de festas que aconteciam depois da celebração das missas católicas. Muito mais frequentes no passado, as celebrações desempenharam um papel agregador, como sugere Gal, líder do quilombo Imbiara e integrante do Conselho Quilombola. Gal conta como na sua juventude, uns trinta anos atrás, as "brincadeiras" eram frequentes, aproveitando-se, sobretudo, dos momentos comunitários propiciados pela missa: "não tinha data certa pra fazer a missa, aí fazia aquela missa e depois juntava todo mundo e fazia uma brincadeira pra dançar. Depois da missa tinha muita gente, aí ia dançar". Gato, outro líder da Imbiara, lembra da festa que Nossa Senhora da Conceição, quando "vinha muita gente de fora, vinha 
orquestra, aí dizia a missa e depois começava a festa e na segunda-feira tinha procissão". Naquela época costumava-se pagar as despesas da festa arrecadando dinheiro com a "esmola cantada", que se tornava outro momento comunitário, capaz de criar uma verdadeira rede festiva, como ele nos conta:

\begin{abstract}
Acontecia um mês antes, que era pra arrecadar dinheiro pra fazer a festa. A esmola cantada saia de casa em casa frequentando as casas, as pessoas davam o dinheiro. Ia de casa em casa em todas comunidades. Na Ponte ainda tem. Ia pra Guaíba, ia pro Kalolé, era da Guaíba ao Kalolé. Ia no Tabuleiro, cada domingo ia pra um lugar. Era de pé, cantando. Tinha, pandeiro, violão, cavaquinho, tamborim. Mas hoje poucos sabem cantar, somente na Ponte.
\end{abstract}

Como indica este relato, num passado ainda recente, redes comunitárias se delineavam através das festividades que garantiam a transmissão do saber e a circularidade das performances festivas. Hoje em dia os quilombos do Kalolé e da Imbiara apresentam uma forte diminuição de católicos e uma presença evangélica que tem sua própria sociabilidade ligada às igrejas pentecostais presentes no local (Assembleia de Deus, Igreja Batista Missionária e Deus é Amor). Como enfatiza Lourival, morador da comunidade do Kalolé: “As festas daqui é quando tem um aniversário (...) porque antigamente tinha as devoções, mas hoje a nossa comunidade aqui, se a gente for separar os católicos e os evangélicos eu acho que tem mais evangélico. Então isso enfraqueceu as festas. $\mathrm{O}$ atual decaimento das celebrações católicas nas comunidades quilombolas percebe-se no abandono das igrejinhas e capelas, cuja atividade e preservação era, no passado, determinante para a organização festiva. Sobre o decaimento dessas práticas, Lourival conta que na comunidade da Fazenda Grande, próxima ao Kalolé, existia uma festa muito apreciada que já não acontece mais: "a Santa Cruz, aonde todo ano tinha missa. Era um festão. $\mathrm{Na}$ época que tinha missa nessa Santa Cruz. Hoje tá lá ainda o lugar que era. É bem próximo. Então a gente ainda tem essas ruínas". Lourival considera, desta forma, o território através das suas memórias festivas, suas palavras indicando claramente a ligação entre a parte material e a parte imaterial do patrimônio quilombola.

Parece claro, assim, para os moradores o motivo do decaimento das festas católicas: muitos dos organizadores antigos já são falecidos e vários dos que ainda estão vivos se tornaram evangélicos. Os interlocutores comentam, ainda, como no passado a população da comunidade Imbiara era maior, propiciando maior afluência nas festividades: no entorno da igrejinha local, depois da missa, era notável, a participação comunitária, sobretudo nos meses de janeiro e fevereiro, quando, finalmente passado o período chuvoso, as celebrações se faziam com mais frequência. Concluindo, pode-se dizer que, em acordo com as narrativas coletadas nas diversas comunidades citadas, um passado mais festivo contrasta com as mais recentes mudanças demográficas e confessionais.

\title{
Conclusão
}

As narrativas apresentadas acenam para a presença da cultura popular e sincrética nas festividades locais atuais e mais antigas. Algumas dessas comunidades são hoje caracterizadas pela forte presença evangélica que parece andar contra a preservação e continuação da cultura festiva local. Comparando essas narrativas com a nossa observação da "inventada" Festa da Ostra, é evidente como este evento se constrói mobilizando uma identidade quilombola segundo um novo assemblage da cultura popular (com as programações de 
samba de roda, de teatro de rua, da religiosidade de matriz africana etc.). Este movimento, que contrasta com a falta de cultura festiva entre os quilombolas evangélicos, não se contenta com uma adesão ao festivo popular tout court. De fato, a Festa da Ostra, querendo performar uma alteridade quilombola (de ex escravos negros) em relação à sociedade nacional, se delineia através de marcadores étnicos para associá-los à memória da luta dos povos dos quilombos contra a escravatura e a opressão. Vão assim se redefinindo os usos da cultura popular, atribuindo-lhe um valor que permite um processo de etnogênese (Arruti, 1997), liderado pelo quilombo Kaonge, onde o carisma de Juvani, Ananias e de outros conselheiros parece fundamental na elaboração de uma agência política que opera fricções da identidade quilombola com o Estado Nacional.

Opondo-se ao esvaecimento da identidade quilombola na generalidade da cultura "popular" ou "rural", Juvani não deixa de sublinhar nas suas falas, a relevância da festa para "fazer" quilombo, em contraste com a "apatia" festiva dos evangélicos (com quem, de qualquer forma, tem uma convivência amigável). A Festa da Ostra, com sua estrutura de festival eco gastronômico moderno e sua dimensão globalizada, torna visível uma identidade quilombola associada a suas múltiplas dimensões locais - produtivas, artesanais, estéticas e artísticas. Em sua constante referência à etnicidade e à luta negra 26, a festa desfruta também dos símbolos religiosos afro-brasileiros, atrelando a eficácia transformativa das performances rituais (o Caruru de Vungi) ao poder transformativo de novos sujeitos políticos (notadamente, das metas obtidas pelo Conselho Quilombola). Já o projeto de revitalização da festa São Roque prevê o desempenho de uma "inventada" tradição griô a partir do resgate da tradicional transmissão oral, segundo modalidades modernas de reflexividade sobre cultura popular, ancestralidade e formas institucionais de preservação do patrimônio imaterial. Em ambos os casos, notamos a construção de uma identidade quilombola cujas dimensões mais significativas escorrem para além de uma simples reconstrução da memória e de saudosismos, pois motivam os agenciamentos no presente. Sobre esta questão, escreve Arruti (1997:23):

\begin{abstract}
os laços das comunidades atuais com grupos do passado precisam ser produzidos hoje, através da seleção e recriação de elementos da memória, de traços culturais que sirvam como os 'sinais externos' reconhecidos pelos mediadores e o órgão que tem a autoridade de nomeação" (grifos do autor).
\end{abstract}

Nas festas estudadas encontramos comportamentos "restaurados" (Schechener, 2013:2), isto é, componentes festivos (de cunho popular, religioso, mas também moderno) rearranjados no contexto das performances de modo a se tornarem únicos e capazes de construir um conjunto de ações, interações e relações específicas. No tocante desta especificidade, como tentamos mostrar, ao mesmo tempo que que tais ações, interações e relações veiculam reflexividade relativas ao patrimônio imaterial, elas constroem o campo étnicoquilombola, segundo um envolvimento das subjetividades e dos afetos nos interesses coletivos e políticos das comunidades. Como é possível inferir do trabalho de Arruti, embora muitos elementos das festas consideradas visem pragmaticamente dar visibilidade à causa quilombola, "as lutas comuns e os rituais retomados ou inventados (mas de qualquer forma partilhados) contribuem para dotar aquelas identidades de uma grande importância normativa, afetiva e valorativa” (1997:28). No caso da Festa de São Roque,

\footnotetext{
${ }^{26}$ Vale lembrar o citado turismo étnico divulgado durante a festa, que tem o emblemático nome "Rota da Libertade".
} 
vimos como o seu resgate foi agenciado pelos próprios orixás, que desfrutando da mediunidade de Juvani, impuseram a retomada das festividades. A revitalização da festa se conjuga, assim, com uma eficácia de cunho ritual (Bassi, 2016) performada pela mãe-de-santo nos moldes da religiosidade afrobrasileiras, que corresponde ao importante valor normativo e valorativo de uma injunção extra-humana (os orixás sempre inspiram Juvani). No caso da Festa da Ostra, finalmente, elementos ritualísticos (o banquete para as entidades africanas) são dinamicamente predicados de modo pontual com o memorável e, sobretudo (já que falamos de festa), com o comemorável: é a história de uma comunidade quilombola compartilhando seus valores e celebrando suas conquistas.

\section{Bibliografia}

ADELL, Nicholas. Patrimoine, éthique, identité. Ricerca Folklorica. Brescia, $\mathrm{n}^{\circ} 62,2011, \mathrm{p} .81-93$.

AMARAL, Rita. As mediações culturais da festa. Revista Mediações. Londrina, 3 (1), jan-jun 1998, p. 13-22.

ARRUTI, José Maurício. A emergência dos 'remanescentes': notas para o diálogo entre indígenas e quilombolas. Mana, Rio de Janeiro, n. 3.2, 1997, p-738 .

ARRUTI, José Maurício. Quilombos. In: SANSONE, Lívio \& Osmundo PINHO (orgs.). Raça: novas perspectivas antropológicas. Salvador: ABA/ Edufba, 2008, p.315-350.

BASSI, Francesca. Atos rituais: eventos, agências e eficácias no Candomblé. Religião e Sociedade, Rio de Janeiro, 36(2), 2016, p. 244-265,

BOISSEVAIN, Jeremy (org.), Revitalizing European Rituals. London and New York, Routledge, 1999.

BOISSEVAIN, Jeremy. Evoluzioni e dinamiche dei rituali di quartiere a Malta: 1960-2000. Dialoghi Mediterranei, Mazara del Vallo, n.5, Janeiro 2014. Disponível em: http://www.istitutoeuroarabo.it/DM/evoluzioni-e-dinamichedei-rituali-di-quartiere-a-malta-1960-2000/. Acesso em 15 de fev.2017.

DUVIGNAUD, Jean. Festas e civilizações. Rio de Janeiro: Tempo Brasileiro, 1983.

FRAGA FILHO, Walter. Encruzilhadas da liberdade: histórias de escravos e libertos na Bahia (1870-1910). São Paulo: Editora da Unicamp, 2006.

HOBSBAWM, Eric \& TERENCE Ranger. A invenção de tradições. Rio de Janeiro: Paz e Terra, 1997.

INGOLD, Tim. Da transmissão de representações à educação da atenção. Educação. Porto Alegre, 33 (1), 2010, p. 6-25. 
ACENO, Vol. 4, N. 7, p. 15-32. Jan. a Jul. de 2017. ISSN: 2358-5587.

Cultura Popular, Patrimônio e Performance (Dossiê).

MARINHO, Thais Alves. As nuances do reconhecimento mussuca: entre a folclorização e a etnicização. In GOUVÊA Dumas, Alexandra e CARVALHO, Clóvis. Corpo Negro. Nadir de Mussuca, Cenas e Cenários de uma mulher quilombola. São Cristóvão: Ed.UFS, 2016, p.153-177.

MOURA, Glória. Festas dos quilombos. Brasília: Editora UnB, 2012.

GOMES DO NASCIMENTO, Danielle \& Maria Ignez NOVAIS. As práticas orais das rezadeiras: um patrimônio imaterial presente na vida dos itabaianenses. Revista Nau Literária. Porto Alegre, v.9, n.1, 2013, p.1-16.

PEIRANO, Mariza. Temas ou Teorias? O estatuto das noções de ritual e de performance. Campos, Curitiba, 7(2), 2006, p.9-16.

PEREZ, Léa. Festa para além da festa. In: PEREZ, Léa et al. (orgs.) Festa como perspectiva e em perspectiva. Rio de Janeiro: Garamond, 2012, p.21-42.

POUGET, Frederic \& Danilo RAMOS. Ancestrais, tartarugas e moisés interface dialógica entre arqueologia e antropologia na etnografia dos hupd'äh (Rio Negro). Revista de Arqueologia Pública, Campinas, 2014, p.6-22.

SCHECHNER, Richard. "Pontos de Contato" revisitados. In: DAWSEY, John et al. (orgs.). Antropologia e performance. São Paulo: Terceiro Nome, 2013, p.3765.

SEVERI, Carlo. Memory, reflexivity and belief. Reflections on the ritual use of language. Social Anthropology, Cambridge, 10-1, 1985, p. 23-40.

SEVERI, Carlo. Procedure per riconoscere gli errori. Antropologia e memoria. In: Doni, Martino. Un’intervista a Carlo Severi. Universitá degli Studi di Bergamo, 2005 (sn).

TAVARES, Fátima. Religião, festa e ritual como agenciamentos possíveis. In: PEREZ Léa et al. (Orgs.) Festa como perspectiva e em perspectiva. Rio de Janeiro, Garamond, 2012, p.119-130.

TAVARES, Fátima e Francesca BASSI. Efeitos, símbolos e crenças. Considerações para um começo de conversa. In: TAVARES, Fátima \& Francesca BASSI. Para além da eficácia simbólica. Estudos em ritual, religião e saúde. Salvador: Edufba, 2013, p.17-28.

TAVARES, Fátima e Francesca BASSI. Diversidade e invisibilidade festiva na Baia de Todos os Santos. In: TAVARES, Fátima \& Francesca BASSI (orgs.). Festas na Baía de Todos os Santos: visibilizando diversidades, territórios, sociabilidades. Salvador, Edufba, 2015, p.255-278.

WAGNER, Roy. A invenção da cultura. São Paulo: Cosac Naify, 2010.

\section{Recebido em 17/05/2017. Aprovado em 12/o8/2017.}

